\title{
Perancangan Mesin Pompa Air Tenaga Surya untuk Mengurangi Konsumsi Listrik Skala Rumahan
}

\author{
Zaenal Arifin $^{1 *}$, Aries Jehan Tamamy ${ }^{1}$, dan Nur Islahudin ${ }^{2}$ \\ ${ }^{1}$ Program Studi Teknik Elektro, Universitas Dian Nuswantoro, Semarang, Jawa Tengah, Indonesia \\ ${ }^{2}$ Program Studi Teknik Industri, Universitas Dian Nuswantoro, Semarang, Jawa Tengah, Indonesia \\ *Corresponding author, e-mail : xzaenal@dsn.dinus.ac.id
}

\begin{abstract}
Abstrak - Salah satu peralatan rumah tangga yang mengkonsumsi daya listrik cukup besar adalah mesin pompa air. Hampir setiap rumah yang memanfaatkan air sumur, menggunakan mesin pompa air untuk menyedot air dari dalam tanah ke dalam bak penampungan air sementara (tandon air). Untuk mengurangi beban listrik dalam pemenuhan kebutuhan distribusi air untuk skala rumah tangga, dapat dilakukan dengan membuat sistem pompa air yang dilengkapi dengan Panel Surya (PV). Panel surya atau PV yang digunakan pada riset ini mempunyai kapasitas 100 WP yang terdiri dari 2 buah PV 50 WP dirangkai secara pararel. PV yang digunakan berjenis monocrystal dengan merek SHINYOKU. Pengujian dilakukan dengan mengukur debit air pompa air dan membandingkannya dengan daya yang dibutuhkan oleh pompa air tersebut. Dalam perhitungan debit air, pompa air mampu mengalirkan air dengan volume 8,5 liter/menit. Daya pompa air diukur dengan menggunakan watt meter, daya yang dibutuhkan oleh pompa air tersebut sebesar 223 watt/hour. Durasi waktu yang dibutuhkan untuk mengisi penuh tandon air berukuran 1000 liter yaitu selama 2 jam atau 119 menit dengan mengkonsumsi 450 watt. Apabila dikalkulasikan selama 1 bulan (30 hari), dengan mamnfaatkan sistem pompa air tenaga surya dapat mengurangi konsumsi daya hingga 13500 watt atau $13,5 \mathrm{Kw}$.
\end{abstract}

Kata Kunci : Mesin Pompa Air, Panel Surya (PV), Daya, Debit Air.

\begin{abstract}
One of the household appliances which consumes quite a large amount of electricity is a water pumping machine. Almost every house that uses well water, uses a water pumping machine to suck water from the ground into a temporary water reservoir (water reservoir). To reduce the electricity load in meeting the needs of water distribution for household scale, can be done by making a water pump system that is equipped with a Solar Panel (PV). Solar panels or PV that are used in this research have a capacity of 100 WP consisting of 2 pieces of 50 WP PV arranged in parallel. The type of PV used is monocrystal with SHINYOKU brand. The testing is done by measuring the output capacity of a water pump and compare it with the power needed by the water pump. In the calculation of water discharge, the water pump is able to pump water with a volume of 8.5 liters / minute. The water pump power was measured using a watt meter, the power needed by the water pump is 223 watt/hour. The duration of time needed to fully fill a 1000 liter water reservoir is 2 hours or 119 minutes consumes 450 watt. If calculated for 1 month (30 days), using a solar water pump system could reduce power consumptions up to $13500 \mathrm{w}$ or $13.5 \mathrm{Kw}$.
\end{abstract}

Keywords : Water Pump, Solar Panel (PV), Power, Output Capasity.

\section{Pendahuluan}

Rencana pencabutan subsidi tarif listrik mengakibatkan biaya yang dikeluarkan oleh masyarakat akan meningkat. Pencabutan subsidi listrik dilakukan secara bertahap mulai dari tahun 2019 hingga 2020[1]. Salah satu peralatan rumah tangga yang mengkonsumsi daya listrik cukup besar adalah mesin pompa air. Dalam Skala rumah tangga, mesin pompa air yang digunakan rata - rata memiliki kebutuhan daya hingga 300 watt/hour[2][3]. Pompa tersebut memiliki kemampuan mengalirkan air dengan debit 5 liter/menit hingga 10 liter/menit tergantung dari panjang serta kedalaman pipa yang masuk ke dalam sumur.

Hampir setiap rumah yang memanfaatkan air sumur, menggunakan mesin pompa air untuk menyedot air dari dalam tanah ke dalam bak penampungan air sementara (tandon air)[4]. Kebutuhan air masing - masing rumah tangga tergantung dari jumlah orang pada setiap rumah. Menurut data yang dikeluarkan oleh kementrian Pekerjaan Umum (PU) kebutuhan air bersih per orang untuk 1 hari adalah $60-70$ liter[5]. Kapasitas 
tandon yang umumnya terpasang pada skala rumahan yaitu sebesar 1000 liter[6]. Tandon tersebut dapat memenuhi kebutuhan air selama 1 hari hingga 2 hari tergantung dari jumlah penghuni dari rumah tersebut. Dengan rata - rata debit air yang mampu disalurkan oleh pompa air tersebut, maka dibutuhkan waktu selama 2 jam hingga 3 jam untuk dapat mengisi tandon tersebut ke kondisi penuh.

Dengan beban listrik sebesar 300 watt/hour, maka konsumsi daya dibandingnkan dengan waktu yang dibutuhkan untuk melakukan pengisian tandon 1000 liter lebih dari 500 watt. Apabila pompa air tersebut menyala 1 hari sekali, total daya yang dibutuhkan untuk pemenuhan air selama 1 bulan (30 hari) lebih dari $15 \mathrm{Kw}$. Untuk mengurangi beban listrik dalam pemenuhan kebutuhan distribusi air untuk skala rumah tangga, dapat dilakukan dengan membuat sistem pompa air yang sumber daya listriknya dipasok oleh sinar matahari. Secara sederhana, sistem tersebut memanfaatkan panel surya sebagai alat konversi sumber cahaya matahari menjadi energi listrik, baterai sebagai perangkat penyimpanan daya sementara, serta pompa air yang dilengkapi dengan inverter agar mampu bekerja dengan sumber arus DC dari baterai[7].

\section{Perancangan Sistem Pompa Air Tenaga Surya}

Rancangan pompa air tenaga surya terdiri dari :

1. Panel surya (PV)

2. Baterai

3. Inverter

4. Mesin pompa air

5. Charger control

\subsection{Panel Surya (PV)}

Panel surya atau (PV) memiliki peranan merubah intensitas sinar matahari menjadi energi listrik. Semakin besar intensitas matahari, maka akan semakin besar pula energi yang dapat dikonversikan[8]. Untuk memenuhi kebutuhan listrik guna mensuplai mesin pompa air melalui baterai, maka diperlukan ukuran yang cukup dalam implementasinya. PV yang digunakan untuk mengkonversi sinar matahari menjadi energi listrik memiliki kapasitas $100 \mathrm{WP}$ yang terdiri dari 2 buah PV 50 WP dirangkai secara pararel. PV yang digunakan berjenis monocrystal dengan merek
SHINYOKU. Dalam waktu satu hari, mampu memperoleh daya maksimum selama 4 jam dan pada cuaca cerah mampu menghasilkan daya hingga 600 watt dalam hitungan hari[9].

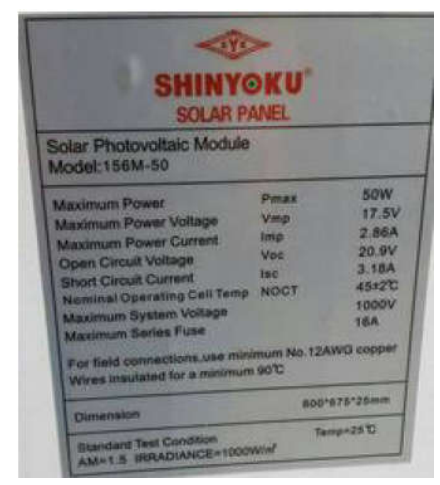

Gambar 1. Spesifikasi Panel Surya

\subsection{Baterai}

Dalam penentuan kapasitas baterai, dilakukan analisa perkiraan penyimpanan baterai, dengan kebutuhan beban harian dalam penggunaan mesin pompa air [10]. Baterai yang digunakan memiliki kapasitas 50 Ampere dengan tegangan $12 \mathrm{~V}$. Baterai tersebut berjenis aki hybrid dengan merek GS HYBRID 50 A. Baterai tersebut dipilih karena perawatan yang mudah serta dapat dilakukan pengisian berulang kali. Selain hal tersebut, kapasitas baterai juga menjadi pertimbangan guna mampu digunakan untuk mensuplai daya mesin pompa air melalui inverter[11].

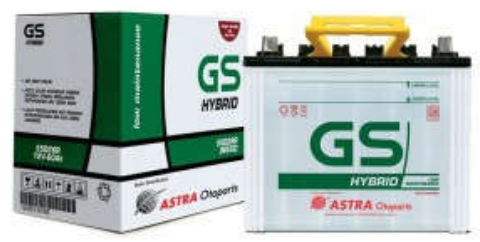

Gambar 2. Baterai GS Hybrid

\subsection{Inverter}

Inverter merupakan peralatan yang berfungsi sebagai pengubah arus DC menjadi AC. Inverter yang baik, memiliki kemampuan konversi dengan effisiensi yang tinggi dan memiliki keluaran gelombang sinus yang baik[12]. Karena beban memiliki kebutuhan daya AC $220 \mathrm{~V} 300 \mathrm{Watt} /$ hour, maka diperlukan inverter untuk mengubah sumber DC dari baterai menjadi AC. Inverter yang digunakan adalah Pure Sine Wave (PSW) dengan merek VISERO 500 watt karena daya yang dibutuhkan untuk melakukan supply ke pompa air 
sebesar 300 watt. Beban motor sangat berpengaruh terhadap kualitas gelombang sinus yang dihasilkan oleh inverter[13]. Apabila gelombang sinus yang dihasilkan tidak memliki kualitas yang bagus, hal tersebut dapat berpengaruh pada putaran motor mesin pompa air[14]. Inverter PSW digunakan karena dapat menghasilkan gelombang sinus yang baik serta effisiensi diatas $90 \%$.

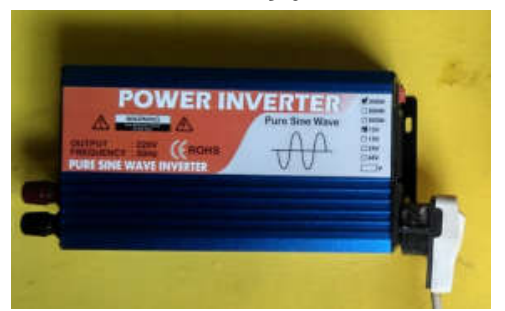

Gambar 3. Inverter PSW VISARO 500 watt

\subsection{Mesin Pompa}

Mesin pompa air digunakan sebagai alat untuk mendistribusikan air dari sumber air (sumur) ke tempat penyimpanan air sementara seperti bak mandi dan tandon air[15]. Kapasitas bak penampungan air memliki ukuran yang bervariasi, umumnya, kapasitas tersebut disesuaikan dengan jumlah anggota keluarga yang ada di suatu rumah. Bak penampungan air umumnya akan diisi setiap hari sekali. Ukuran tandon yang digunakan pada penelitian ini memliki kapasitas 1000 liter. Untuk mendisitribusikan air, digunakan pompa sumur dangkal dengan tingkat delaman sumur 12 meter dari permukaan tanah. Peneliti menggunakan pompa air Shimizu PS-135 E. Pompa tersebut memiliki spesifikasi seperti pada tabel di bawah ini.

Tabel 1. Spesifikasi Shimizu PS-135 E

\begin{tabular}{|c|c|}
\hline Output & 125 watt \\
\hline Input & 0.3 Kilo watt \\
\hline Panjang Pipa & $9 \mathrm{~m}$ \\
\hline Total Head Max. & $33 \mathrm{~m}$ \\
\hline Head & $20 \mathrm{~m}$ \\
\hline Kapasitas & $28 \mathrm{l} / \mathrm{min}$ \\
\hline
\end{tabular}

Gambar 4. Shimizu PS-135 E
Proses pengisian daya dari PV ke baterai, dilakukan dengan peralatan charger control. Di dalam charger control terdapat Maximum Power Point Tracking (MPPT) yang bekerja dengan metode Pulse Width Modulation (PWM). Charger control juga memiliki peranan memutus aliran daya dari PV ketika kondisi baterai telah penuh secara otomatis[16]. Charger control yang digunakan memiliki kapasitas 30 A dan dilengkapi dengan indikator kapasitas baterai[17].

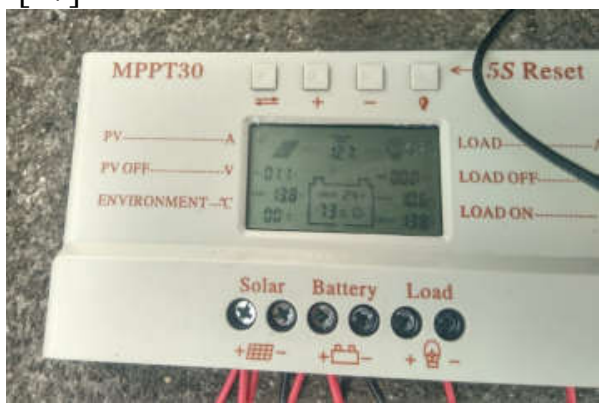

Gambar 5. Charger Control

\section{Hasil dan Pembahasan}

Seluruh peralatan yang dibutuhkan kemudian dirangkai seperti pada gambar berikut.

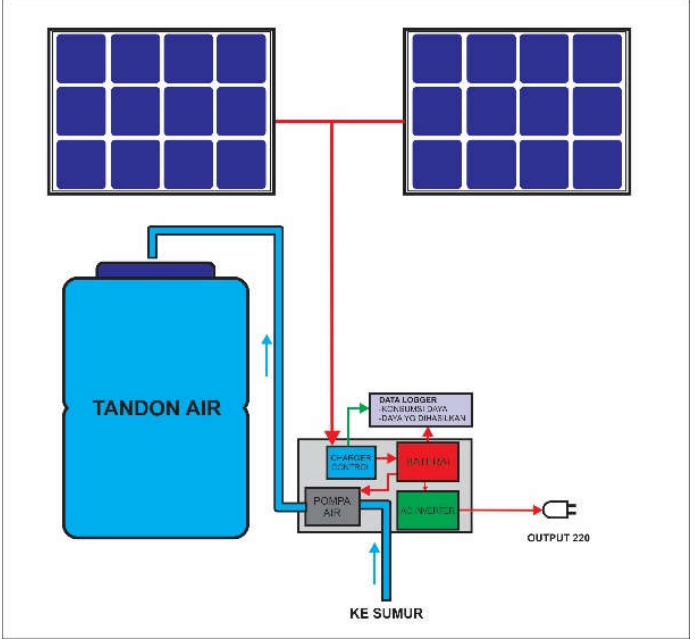

Gambar 6. Rangkaian Pompa Air Tenaga Surya

Pada tahap awal pengujian, PV merubah energi sinar matahari menjadi energi listrik untuk mengisi baterai. Dengan pemanfaatan 100 WP panel surya, dalam1 hari mampu mengisi baterai secara penuh. Pengisian baterai dimulai pada jam 07.00 hingga jam 17.00. Antara jam 07.00 hingga 09.00 pengisian baterai berjalan efektif dengan rata - rata lux sebesar 6000-10.000 lux. Setelah jam 9.00 lux meningkat hingga lebih dari 10.000 lux sehingga pengisian baterai menjadi optimum sampai jam

\subsection{Charger Control}


16.00. Setelah jam 16.00 pengisian baterai menjadi kurang optimum karena lux mulai turun.

Tabel 2. Pengisian Baterai Menggubakan PV $100 \mathrm{WP}$

\begin{tabular}{|c|r|r|r|}
\hline No & Jam & \multicolumn{1}{c|}{ Lux } & $\begin{array}{c}\text { Tegangan } \\
\text { (V) }\end{array}$ \\
\hline 1 & $05-06$ & 119 & 12,68 \\
\hline 2 & $06-07$ & 2672 & 13,11 \\
\hline 3 & $07-08$ & 5946 & 14,27 \\
\hline 4 & $08-09$ & 8050 & 14,74 \\
\hline 5 & $09-10$ & 10396 & 14,69 \\
\hline 6 & $10-11$ & 11168 & 14,55 \\
\hline 7 & $11-12$ & 26716 & 14,49 \\
\hline 8 & $12-13$ & 54578 & 13,79 \\
\hline 9 & $13-14$ & 56455 & 13,44 \\
\hline 10 & $14-15$ & 54877 & 13,39 \\
\hline 11 & $15-16$ & 18770 & 13,31 \\
\hline 12 & $16-17$ & 7450 & 13,02 \\
\hline 13 & $17-18$ & 921 & 12,74 \\
\hline 14 & $18-19$ & 0 & 12,63 \\
\hline
\end{tabular}

Pengujian dilakukan dengan mengukur kecepatan debit air yang mampu dialirkan oleh pompa air dengan daya yang dibutuhkan oleh pompa air tersebut. Dalam perhitungan debit air, pompa air mampu mengalirkan air dengan volume 8,5 liter/menit.

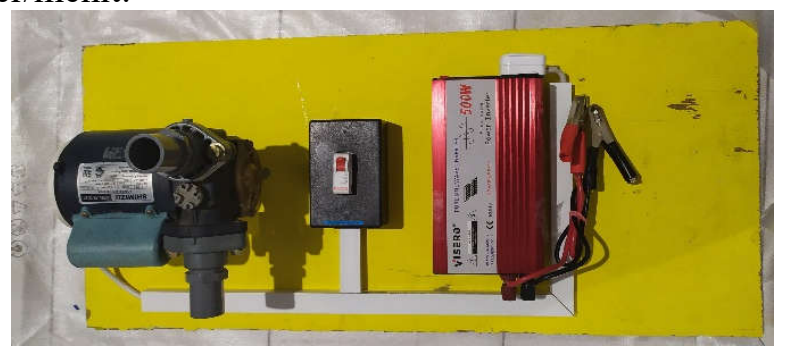

Gambar 7. Perakitan Inverter Dengan Mesin Pompa Air

Penurunan kapasitas debit air dipengaruhi oleh panjang pipa dari sumber air menuju bak penampungan air sepanjang 28 meter, dengan posisi tandon berada pada ketinggian 5 meter diatas tanah.

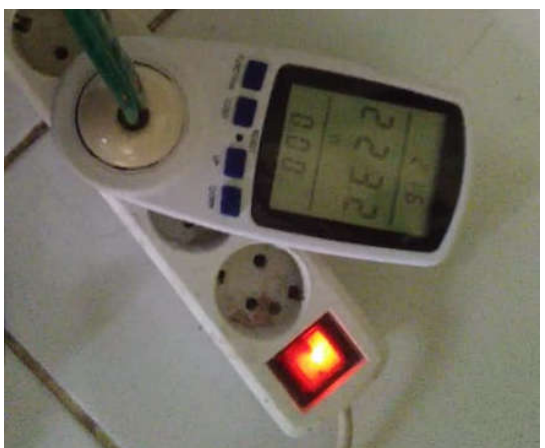

Gambar 8. Pengukuran Daya Pompa Air
Dengan menggunakan watt meter, daya yang dibutuhkan oleh pompa air tersebut sebesar 223 watt/hour. Konsumsi daya yang muncul pada watt meter merupakan daya rata - rata yang diserap oleh beban setiap jamnya (wh). Pada menu watt meter terdapat perekaman jumlah daya yang mengalir dalam durasi waktu yang dapat disesuaikan. Durasi waktu yang dibutuhkan untuk mengisi penuh tandon air berukuran 1000 liter yaitu selama 2 jam (119 menit). Dengan durasi waktu tersebut, daya yang dikonsumsi mencapai 450 watt. Dan kapasitas baterai tersisa $20 \%$.

\section{Kesimpulan}

Pengujian serta pengambilan data mesin pompa air tenaga surya dapat dilakukan dengan baik. Pompa air mampu mengalirkan air dengan debit air mencapai 8,5 liter/menit. Dengan daya rata - rata 223 watt/jam. Durasi waktu yang dibutuhkan untuk mengisi tandon 1000 liter yaitu 119 menit (2 jam) sehingga mengkonsumsi daya 450 watt dengan kapasitas baterai tersisa $20 \%$. Agar sistem pompa air dapat berjalan lebih baik lagi, perlu penambahan kapasitas baterai agar baterai tidak cepat rusak karena sisa daya yang tersimpan pada batarei terlalu rendah. Apabila dikalkulasikan selama 1 bulan (30 hari), dengan memanfaatkan mesin pompa air tenaga surya dapat menghemat hingga 13500 watt atau $13,5 \mathrm{Kw}$.

\section{Ucapan Terima Kasih}

Terima kasih penulis sampaikan kepada Lembaga Penelitian dan Pengabdian Masyarakat (LPPM) Universitas Dian Nuswantoro serta Fakultas Teknik Universitas Dian Nuswantoro karena telah memfasilitasi penelitian yang penulis lakukan.

\section{Daftar Pustaka}

[1]. Merdeka.com "Subsidi Dicabut, Tarif Listrik Pelanggan 900 VA Naik Mulai Januari 2020" 4 September 2019 diakses pada 3 Desember 2019.

[2]. Santosa I. "Analisa Intensitas Konsumsi Listrik Melalui Audit Energi Skala Rumah Tangga". Jurnal Universitas Pncasakti Tegal, vol. 15 No. 2. Oktober 2017.

[3]. Sanurya P.P, "Audit Energi dan Analisis Peluang Penghematan Konsumsi Energi Listrik pada Rumah Tangga". MEDIA MESIN, Vol. 15 No. 1 ISSN 14114348. Januari 2014.

[4]. Arjuna CS, Maulana Y, Akib A. "Analisis Kinerja Pompa Tanah Agar Sesuai Dengan Kapasitas Feed yang Dibutuhkan JIG Primer Pada Kapal Isap Produksi 17 di Laut Cupat Luar, Unit Penambangan Laut Bangka PT Timah (Persero) Tbk". 2017. 
[5]. Peraturan Menteri Pekerjaan Umum. "Standar Pelayanan Minimal Bidang Pekerjaan Umum dan Penataan Ruang". Kementrian Pekerjaan Umum No. 14/PRT/M/2010.

[6]. I Wahyudi. "Analisis Perbandingan Pompa Guna Pemenuhan Kebutuhan Air Bersih PDAM Kota Probolinggo". Skripsi Mahasiswa Teknik Mesin Universitas Jember, Jawa Timur 2013.

[7]. Iqtimal Z., Ira D. S., Syahrizal. "Aplikasi Sistem Tenaga Surya Sebagai Sumber Tenaga Listrik Pompa Air". KITEKTRO : Jurnal Online Teknik elekktro. Vol. 3 No. 12019 Hal. 1-8 e-ISSN : 2252-7036.

[8]. Hasan., Hasnawiya. "Perancangan Pembangkit Listrik Tenaga Surya di pulai Saugi". Skirpsi mahasiswa repository Universitas Hasanuddin.

[9]. Z Arifin, H Rahadian. "Rancang Bangun Stand - Alone Automatic Rain Gauge (ARG) Berbasis Panel Surya". JNTE. 2302-2949. 2017.

[10]. Chico H. B. A. Teguh E. MiftahulA. "Prototype Sistem Pompa Air Tenaga Surya Untuk Meningkatkan Produktivitas Hasil Pertanian". ABDIMAS Vol. 21 No. 2 2017.

[11]. MT Afif, Ayu PP. "Analisis Perbandingan Baterai Lithium-Ion, Lithium-Polymer, Lead Acid dan NickelMetal Hydride pada Penggunaan Mobil Listrik". Jurnal Rekayasa Mesin Vol. 6, No.2 2015. 2477-6041Yamin L, Wanming C. Implementation of Single Precision Floating Point Square Root on FPGAs. IEEE Symposium on FPGA for Custom Computing Machines. Napa. 226-232. 2008.

[12]. Agus T. A. Indra T.P. Wayan A. W." Perbandingan Penggunaan Motor DC Dengan AC Sebagai Penggerak Pompa Air Yang Disuplai Oleh Sistem Pembangkit Listrik Tenaga Surya (PLTS)". ProsidingConference on Smrat-Green Technology in Elektrical and Information Systems (CSGTEIS) Universitas Udayana Bali ISBN : 978-602-7776-72-2. 2013

[13]. Lukman S. Ma'un B. "Pengaruh Distorsi Tegangan Catu Pada Efisiensi Motor Induksi 1,5 KW". Modern Electrical Engineering Technology and Its Applications Seminar (MEETAS 2010) Bandung 20 Maret 2010.

[14]. Robby F. Soeprapto, Hery P. "Pengaruh Bentuk Gelombang Sinus Termodifikasi (Modified Sine Wave) Terhadap Unjuk Kerja Motor Induksi Satu Fasa". Repository skripsi mahasiswa Universitas Brawijaya.

[15]. Gede I.P. Wayan A.W. Nyoman S. "Rancang Bangun Sistem Pengangkatan Air Menggunakan Motor AC dengan Sumber Listrik Tenaga Surya". Seminar Nasional dan Expo Teknik Elektro Universitas Udayana 2014. ISSN: 2088-9984.

[16]. Angelina E. T. A. J. "Sumber Energi Listrik dengan Sistem Hybrid (Solar Panel dan Jaringan Listrik Pln)". Jurnal Widya Teknik Vol. 10 No. 1 Hal. 42 - 53. 2011.

[17]. AJ Tamamy, Z Arifin, A Amalia. "Desain Low-Cost Sistem Monitoring Pengukuran Potensi Tenaga Matahari dan Tenaga Angin”. Jurnal Rekayasa Elektrika (JRE), Universitas Syiah Kuala, Aceh. 2019.
Biodata Penulis

Zaenal Arifin, staff pengajar di Universitas Dian Nuswantoro Semarang. Menempuh pendidikan S1 Teknik Elektro di Universitas Dian Nuswantoro Semarang dan menempuh pendidikan S2 Electrical and Computer Engineering di South China University of Technology (SCUT).

Aries Jehan Tamamy, staff pengajar di Universitas Dian Nuswantoro Semarang. Menempuh pendidikan S1 Teknik Elektro di Universitas Dian Nuswantoro Semarang dan menempuh pendidikan S2 Electrical and Computer Engineering di South China University of Technology (SCUT).

Nur Islahudin, staff pengajar di Universitas Dian Nuswantoro Semarang. Menempuh pendidikan D3 Teknik Mesin di Politeknik Negeri Semarang, menempuh pendidikan S1 Teknik Industri di Universitas Pancasila, dan menempuh pendidikan S2 Teknik Industri di Institut Teknologi Bandung (ITB). 